\title{
A nova pedagogia da hegemonia no contexto da globalização
}

José Luis Sanfelice

Professor Titular da Unicamp

\section{Resumo}

O presente texto tem por pressuposto teórico a determinação das práticas e teorias pedagógicas, bem como das controvérsias epistemológicas, pela estrutura e superestrutura indissociáveis vigentes. O cenário é o da globalização econômica e cultural. Nesse cenário, destaca-se a pedagogia da hegemonia visando decifrar suas implicações na construção de um novo homem e de um novo consenso ideológico, político e social. Conclui-se que a pedagogia da hegemonia, desde o Estado educador, passando pelas igrejas, mídias e ONG's, tenta sedimentar a "ordem" mundial capitalista-burguesa como algo inevitável.

Palavras-chave: Globalização; Pedagogia da Hegemonia; Educação; Pedagogia do Consenso.

\begin{abstract}
This paper has the theoretical assumptions in determining the practical and pedagogical theories, the controversies in the current epistemological and inseparable relationship between structure and superstructure. The scenario is the economic and cultural globalization. In this scenario, we highlight the teaching of hegemony that seeks to decipher their implications in the construction of a new man and a new ideological consensus, political and social. We conclude that the pedagogy of hegemony from the Educator State, through churches, media and ONGs are trying to consolidate the "order" of the bourgeois-capitalist world as inevitable.
\end{abstract}

Keywords: Globalization; Pedagogy of the hegemony; Education; Pedagogy of Consensus. 
arto do pressuposto que o conjunto de práticas e teorias
pedagógicas, bem como as controvérsias epistemológicas
contemporâneas fazem parte e recebem suas determinações de uma realidade estrutural e superestrutural indissociáveis. As teorias nunca são meras teorias, as práticas não são simples práticas e as controvérsias epistemológicas estão longe de se constituírem em diletantismos acadêmicos. Quer dizer, tudo isto porta densidades de interesses, de objetivos, dentro de certos contextos históricos específicos. Há um cenário histórico onde tudo isto acontece. Para não me alongar em preliminares, há um cenário atual que se convencionou denominar de globalização econômica e cultural. Na verdade, faço aqui uma simplificação de algo muito complexo, mas entendo que todos estão cientes, cada um a sua maneira, quando anuncio o cenário da globalização. Tomo os cenários da globalização econômica capitalista e o da mundialização da cultura em suas manifestações plurais para fazer a afirmação que faço a seguir: não se pode usar a expressão globalização econômica e cultural como se fosse uma única coisa em todo o mundo. Cada um vive a globalização à sua maneira, desde os países que comandam a globalização até a periferia dos globalizados. Não é uma coisa idêntica em toda parte. Apesar disso, faço a opção de não falar de teorias e práticas pedagógicas contemporâneas porque, hoje, elas expressam certa identidade, mesmo que não seja possível perceber em um primeiro momento. A que se pode atribuir o fato de uma grande identidade? Penso que ela decorre da existência do que alguns autores vêem denominando de pedagogia da hegemonia e que é sustentada por uma determinada epistemologia. A pedagogia da hegemonia acompanha, como um elemento superestrutural, toda a base material globalizada a ela correspondente, mesmo com a ressalva que essa não é igual para todo mundo. Em sendo uma pedagogia da hegemonia, ela imiscuí-se nas teorias e praticas pedagógicas atuais e mais ou menos aos poucos e, de forma subliminar, as contamina. Só as pedagogias de resistência, ou as que se propõem a agir na contra hegemonia buscam se diferenciar. Fora isso, cada vez há maior consenso em torno da pedagogia da hegemonia que, em ultima 
instância, responde aos interesses do capital e da sua lógica. Pode-se dizer da pedagogia da hegemonia que ela disputa a direção da educação, dos aparelhos de estado que podem servi-la, e que por convencimento, busca estabelecer o consenso. Essa pedagogia não se esgota no campo escolar, ela está posta no âmbito geral da sociedade e em várias instituições. Pode-se dizer que a pedagogia da hegemonia é gestada pelas classes dirigentes, as classes dominantes do capitalismo. O gerenciador dessa pedagogia é o Estado educador que a implementa nas redes estatais de ensino e em outras redes que também compartilham dela. O Estado educador estabelece assim uma grande ação pedagógica sobre a sociedade civil. Mais do que nunca, as igrejas, a maioria das mídias, os sindicatos e inúmeras associações são instados na mesma tarefa pedagógica de manter o status quo capitalista e burguês. A pedagogia da hegemonia é a pedagogia da conservação da sociedade burguesa e vem se estruturando desde os primórdios da escola estatal, gratuita, laica, obrigatória e disfarçada sobre o rótulo de escola pública (Sanfelice, 2005, p.89-105). Mas chegamos ao fim do século XX com um quadro bem diferente daquele no qual essa escola estatal se instituiu. Faço a seguinte citação sobre o final do século XX:

O fim da Guerra Fria, a crise estrutural de acumulação capitalista e o nível de racionalização alcançado pelo modo de produção social capitalista nas décadas finais do século XX, consubstanciado na mundialização da produção, na difusão do paradigma da acumulação flexível de organização produtiva, assim como na introdução e na difusão aceleradas da microeletrônica e da informática na organização do trabalho e no cotidiano dos cidadãos, determinaram a elaboração de um novo tipo humano, de um novo homem coletivo, conforme aos novos requerimentos da reprodução das relações sociais vigentes. Por outro lado, o desemprego estrutural, a precarização das relações de trabalho e das condições de vida de um contingente cada vez maior de trabalhadores levam o capital a redefinir suas estratégias de busca do consenso da maioria das populações no limiar do século XXI. (Neves \& Sant'Anna, 2005, p. 32).

Todos se lembram dos processos de reformas dos Estados, mundialmente, e que desde os anos 80, eles assumiram novos formatos como educadores da sociedade civil. O Estado de bem estar social perdeu espaços para o estado liberal e, de produtor de bens e serviços, assumiu a função de coordenador das atividades privadas da sociedade civil. De 
promotor que era do consumo da força de trabalho pelo capital, o Estado passou a ser provedor de serviços sociais para uma parcela da sociedade, os excluídos, que agora é aquele contingente que apresenta as condições objetivas para desestabilizar o consenso burguês.

Para o restante da população o Estado configura-se como estimulador das iniciativas privadas de prestação de serviços sociais e de novas formas de organização social que desatrelam várias ações de descriminação e das desigualdades de classes. Então, temos uma mudança profunda, que por ser tão substantiva, o capital redefiniu o papel do Estado na dimensão de educador da sociedade civil. Se voltarmos às bases teóricas das reformulações do Estado, encontramos Hayek e Friedman, atualizados por Giddens com a proposta da terceira via, a nova social democracia. O Estado se redefine de fato, de bem estar social para neoliberal e aí é que a pedagogia da hegemonia vai fazer sucesso porque apregoa que todos serão incluídos. Trata-se apenas de uma questão de tempo. As classes dirigentes e dominantes, por sua vez, mostrarão seu poder de doação (Sanfelice, 2008, p.65-83).

A pedagogia da hegemonia incentiva as soluções individuais. Para a obtenção do consenso estimula a democracia representativa e investe em um modelo novo de cidadania nos moldes da ordem estabelecida o quê acontece de forma mais intensa e menos perceptiva. A pedagogia da hegemonia afasta as relações sociais do eixo capital-trabalho e que é a origem fundamental da exploração, para estimular os movimentos que não focam esta exploração. Por exemplo: os movimentos de defesa das mulheres, das raças, das crianças, dos homossexuais e do meio ambiente. Isso está sendo mundialmente incentivado e desfoca todas as relações e análises da tensão capital/trabalho. Esta pedagogia faz de conta que o capital está preocupado com as relações de raça, de gênero e escamoteia que o capital visa explorar o trabalho, o trabalhador, não importando se é branco, negro, índio ou mulher. Escamoteia que o central é a exploração do trabalho. Para o capital, o trabalhador não tem sexo, raça, gênero: ele é somente produtor de mais valia. Hoje, o imaginário social está desconectado desse eixo. 
A pedagogia da hegemonia faz um forte trabalho para promover o respeito às diferenças porque ele consolida o principio liberal do indivíduo, hoje levado ao extremo do individualismo. Ao Estado resta o papel pedagógico de impulsionar uma cultura cívica, por meio da renovação organizativa da sociedade civil, visando consolidar a coesão social, o empreendedorismo e o voluntariado. A pedagogia da hegemonia incentiva a parceria entre o público e o privado, abrindo margem para as ONG's. O Estado, em sua função educativa, deve priorizar a formação de novas subjetividades que queiram assumir responsabilidades coletivas, eliminando as resistências à ordem burguesa. Os indivíduos - esta é uma palavra de ordem burguesa - devem se tornar flexíveis. Aquele que não for flexível, não está na contemporaneidade. Pelas suas características, o que esta concepção tem por objetivos práticos?

1. Construir uma consciência política que não permita ao individuo entender sua real função social no mundo a partir da sua posição nas relações de produção. Quando vejo certas posturas pós- modernas que despolitizam tudo, penso que elas fazem parte da pedagogia da hegemonia, fazem parte da pedagogia da manutenção.

2. Induzir à percepção de que suas qualidades são geradas pela capacidade suprema de se autogovernar e de que é possível definí-las independente das condições concretas que nos envolvam. Uma literatura de auto-ajuda que confirma o individualismo.

3. Orientar e estimular a possibilidade de associação a outros indivíduos para participação em movimentos políticos mais simples: "A escola da família", por exemplo. Todo mundo vai para a escola, mas não é para definir a política educacional. Você é chamado para ficar no processo de realização simples e localizada. Pretende-se romper com a 'apatia política', com o isolamento, para criar pressupostos necessários a um tipo determinado de participação na vida social e política, sem que isso signifique incentivo a outra perspectiva política, de superação do status quo.

Quando a pedagogia da hegemonia admite o desemprego, a pobreza, ela explica isso pela ótica do infortúnio pessoal. Não há explicação de 
ordem macro (Neves, 2005).

Vamos agora à questão epistemológica. Aonde se fundamenta a pedagogia da hegemonia? Na teoria do capital humano difundida desde os anos 60 e, agora, reformulada na teoria do capital social.

O capital humano mais o capital social, entendido como aquele acúmulo que pequenos grupos conseguem ter, é o remédio para o capitalismo perverso. Se você educasse as pessoas e elas se educassem, o capitalismo ficaria cada dia melhor. Não se discute a relação capital trabalho. Nessa lógica são necessárias ações que assegurem a formação intelectual, moral, ética, política e técnica de todas as pessoas, com ênfase na competência cognitiva e emocional. Uma educação que difunda novos hábitos mentais e comportamentais que tornem os indivíduos abertos, acriticamente, às exigências de novas competências. A estratégia de realização é a afirmação da escola e de outros espaços educativos como instrumentos de formação do intelectual urbano, tendo na concepção de mundo burguesa, o eixo central. Por intermédio das reformas educacionais, que seja realinhado todo o processo formativo, a partir das novas exigências do capital monopolista e diminuídas, ao máximo, as possibilidades de difusão da contra-hegemonia no espaço escolar. Temas antigos como cidadania, igualdade, democracia e temas novos como empreendedorismo, responsabilidade são tratados sob uma abordagem pedagógica que os distancia do conflito antagônico de construção social. Se todos puderem ser solidários com todos, não haverá conflito. Mas isso significa superar a exploração? Não. Se todos puderem ser trabalhadores voluntários, não é preciso ficar brigando pelo trabalho assalariado, que é a única coisa que o trabalhador tem para vender. Trata-se de uma ação orientada por uma concepção pedagógica que cria novas ancoragens teóricas e simbólicas que serão mediações entre sujeito e realidade social em uma perspectiva da sua conservação. A proposta não se limita a difundir imediatamente os valores dominantes a partir da incorporação de valores sociais. Enquanto, o pensamento liberal tradicional agia de acordo com a utopia, os homens poderiam ser todos iguais se cumprissem as leis de mercado, a nova 
proposta considera que isso não seria mais possível. As novas ações devem estar orientadas para gerenciar o sofrimento por meio do amparo social: os "programas paliativos focados" têm metas especificas.

Há uma matriz teórica e epistemológica que orienta a pedagogia da hegemonia: é o liberalismo travestido de neo. O neo não acrescenta nada, é apenas a atualização da visão burguesa de sociedade.

Se fizermos uma análise das agencias multilaterais, Banco Mundial, UNESCO, pelo gerenciamento que elas fazem das políticas educacionais, bem como os Estados vão se obrigando a cumpri-las, encontraremos lá, claramente, a matriz neoliberal sustentando o que é a pedagogia da hegemonia. No Brasil, se considerarmos desde o governo Collor até os dias de hoje, vê-se, nas políticas educacionais, uma acomodação sistemática às políticas destas agências. Quem está ditando o ordenamento educacional é o capital e a determinação está acima dos Estados.

Por que instituições como a mídia, as igrejas e outras organizações vão sendo cooptadas pela pedagogia da hegemonia? Por que a rede Globo de TV anuncia que a escola que dá certo é aquela que é adotada? É um exercício de sincronicidade em função da pedagogia da hegemonia.

Formar para o mercado o trabalhador flexível, mas para qual trabalho? Não há uma crise estrutural de empregos? (Mészaros, 2005). Esta educação vem sendo propagada por diferentes meios, mas a escola continua sendo o seu espaço privilegiado. O novo homem deve se responsabilizar individualmente pela pobreza e pela conservação do meio ambiente. O novo homem deve dedicar parte de seu tempo livre para o trabalho voluntário e, hoje, o voluntariado conta ponto para o currículo.

À escola é transmitida a tarefa de exercer a formação da cidadania de qualidade nova, a partir da qual o espírito de competitividade deve ser incentivado em paralelo ao de solidariedade. Portanto, se a questão está focada nesta relação, a questão das classes não é a principal. Se os trabalhadores podem todos competir entre si, serem solidários entre si, a relação capital-trabalho não aparece.

Cada um de nós é responsável em amenizar um pouco da miséria e o 
capital prepara o trabalhador também para o desemprego.

No Brasil, a partir dos anos 90, não é para se estranhar que o foco das reformas escolares tenha sido a reformulação da formação da classe trabalhadora para ela aceitar a nova cidadania e a formação para o trabalho adequado à re-estruturação produtiva e o desemprego estrutural.

Na sala de aula qual é a prática? É a pedagogia dos resultados. Todo um sistema de avaliação montado não para medir conhecimento, só resultados. Qual é o cerne que orienta esta pedagogia? É o aprender a aprender de competências e habilidades. Este é o binômio: competências e habilidades. Você tem que ter a competência de saber usar o computador, mas não precisa saber nada sobre a ciência da computação. Por que as Agências exigem a universalização do ensino fundamental nas políticas de Estado? Porque virou uma estratégia de inclusão das classes trabalhadoras na sociedade tecnológica, não na sociedade do conhecimento. É a formação para o trabalho simples, não para o complexo.

Essa pedagogia trata a ordem vigente de forma naturalizada, como se tudo isso fosse inevitável. Como a chamada pós-modernidade chancela esta pedagogia? Na falta de historicidade, na despolitização, em não considerar a ideologia que isto carrega, em recomendar que a realidade deva ser compreendida a partir da sua subjetividade. Para que serve a ciência, já que é a sua subjetividade que vai explicar? Tudo tem que ser desfocado.

\section{Referências}

MÉSZAROS, I. A educação para além do capital. São Paulo: Boitempo Editorial, 2005, 77p.

NEVES, L. M. W. \& SANT'ANNA, R. Introdução: Gramsci, o Estado educador e a nova pedagogia da hegemonia. In: NEVES, Lúcia M. W. (org.). $A$ nova pedagogia da hegemonia. Estratégias do capital para educar o consenso. São Paulo: Xamã, 2005, p. 19-39.

NEVES, L. M. W (org.). A nova pedagogia da hegemonia. Estratégias do capital para educar o consenso. São Paulo: Xamã, 2005, 311p.

SANFELICE, J. L. Da escola estatal burguesa à escola democrática e popular: considerações historiográficas. In: LOMBARDI, J. C.; SAVIANI, D.; 
NASCIMENTO, M. I. M. (orgs.). A escola pública no Brasil. História e historiografia. Campinas: Autores Associados: HISTEDBR, 2005,p.89-105.

SANFELICE, J. L. Transformações no Estado-nação e impactos na educação. In: LUCENA, C. (org.). Capitalismo, Estado, educação. Campinas: Alínea, 2008, p.65-83. 